\title{
Human Factors Explain the Increased Losses from Weather and Climate Extremes*
}

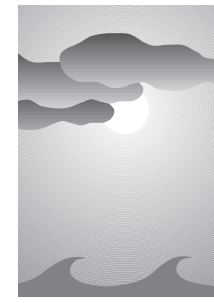

\author{
Stanley A. Changnon, ${ }^{+}$Roger A. Pielke Jr.," David Changnon, ${ }^{@}$ \\ Richard T. Sylves, ${ }^{\star}$ and Roger Pulwarty,**
}

\begin{abstract}
Societal impacts from weather and climate extremes, and trends in those impacts, are a function of both climate and society. United States losses resulting from weather extremes have grown steadily with time. Insured property losses have trebled since 1960, but deaths from extremes have not grown except for those due to floods and heat waves. Data on losses are difficult to find and must be carefully adjusted before meaningful assessments can be made. Adjustments to historical loss data assembled since the late 1940s shows that most of the upward trends found in financial losses are due to societal shifts leading to ever-growing vulnerability to weather and climate extremes. Geographical locations of the large loss trends establish that population growth and demographic shifts are the major factors behind the increasing losses from weather-climate extremes. Most weather and climate extremes in the United States do not exhibit steady, multidecadal increases found in their loss values. Without major changes in societal responses to weather and climate extremes, it is reasonable to predict ever-increasing losses even without any detrimental climate changes. Recognition of these trends in societal vulnerability to weather-climate extremes suggests that the present focus on mitigating the greenhouse effect should be complemented by a greater emphasis on adaptation. Identifying and understanding this societal vulnerability has great importance for understanding the nation's economy, in guiding governmental policies, and for planning for future mitigative activities including ways for society to adapt to possible effects of a changing climate.
\end{abstract}

\section{Introduction}

Recent years have seen a tremendous increase in economic losses from weather hazards. Since 1987, more than 360 U.S. weather events each produced losses in excess of $\$ 5$ million with several record set-

\footnotetext{
*This is the fourth of five papers in the "Understanding Changes in Weather and Climate Extremes" series.

+Atmospheric Environment Section, Illinois State Water Survey, Champaign, Illinois.

\#Environmental and Societal Impacts Group, National Center for Atmospheric Research, Boulder, Colorado.

${ }^{\circledR}$ Geography Department, Northern Illinois University, De Kalb, Illinois.

\&Department of Political Science, University of Delaware, Newark, Delaware.

**Office of Global Programs, NOAA, Silver Springs, Maryland. Corresponding author address: Stanley A. Changnon, Illinois State Water Survey, 2204 Griffith Dr., Champaign, IL 61820.

E-mail: schangno@uiuc.edu

In final form 22 July 1999.

C2000 American Meteorological Society
}

ting catastrophes including the drought of 1988-89 with losses reaching $\$ 39$ billion, Hurricane Andrew in 1992 costing $\$ 30$ billion, and the flood of 1993 with losses of $\$ 19$ billion (CACNH 1999). The insured property losses due to weather extremes (Fig.1) have grown steadily from $\$ 25$ million a year in the early 1950 s to more than $\$ 5$ billion a year in the 1990 s. These losses and their underlying causes have become the major focus of the insurance industry in the United States and beyond (Roth 1996; American Insurance Association 1999). The damages from these events also brought forth record government payments for relief and assistance at a time when controlling the budget has become a national goal (Sylves 1996; Bi-Partisan Task Force 1996). The 1995 heat wave killed 1100 persons, awakening society to another growing atmospheric threat (Changnon et al. 1996). A 1997 weather impacts workshop found annual U.S. losses to extreme weather and climate conditions total in the tens of billions of dollars and thousands of casualties (Pielke 1997).

These weather losses helped raise alarm over the possibility that the recent increases were due to a shift- 


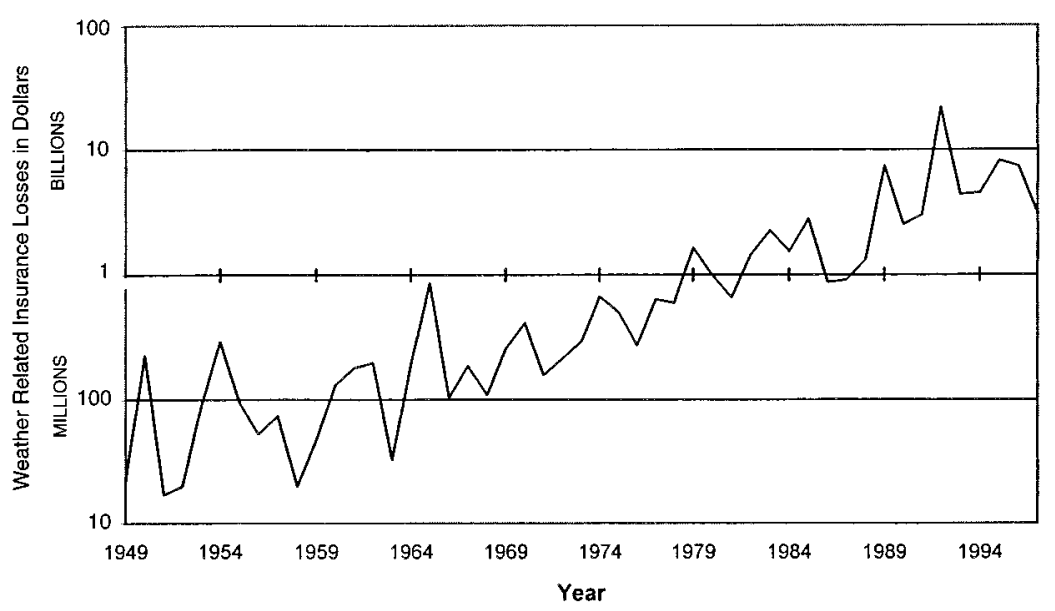

FIG. 1. Annual losses (in 1997 dollars) to insured property in the United States from weather extremes during 1949-97 (Changnon et al. 1997). annual number of catastrophes grew from 10 per year in the 1950 s to 35 annually in the 1990s (Changnon 1999a). The 1990-97 total insured property losses were $\$ 49$ billion, and federal relief payments for weathercaused disasters were $\$ 12$ billion. The 1990s experienced a record number of damaging storms. Those causing property insurance losses $>\$ 100$ million occurred 72 times during 1990-96, whereas only 142 such $\$ 100$ million storms had occurred in the preceding 40 years (Changnon 1999b). However, the weather events causing losses $>\$ 1$ billion have not been increasing in frequency over time and these 22 ing climate (Lecomte 1993; Flavin 1994; American Insurance Association 1999). There has long been scientific concern that a change in climate due to anthropogenic activities would include an increase in the frequency and/or intensity of weather and climate extremes. Changes in either could have major societal impacts. The Intergovernmental Panel on Climate Change (IPCC) addressed the issue on a global scale in its 1995 assessment, declaring "Overall, there is no evidence that extreme weather events, or climate variability, has increased in a global sense through the 20th Century" (IPCC 1996). Regardless of the potential global warming relationship, the trends in losses provide strong motivation for the government and weather-sensitive commerce and business interests to better define and identify the causes for the trends in weather extremes in order to respond effectively.

This paper first examines the trends in the societal and economic impacts related to weather-climate extremes. This is followed by a review of data sources that measure these impacts. Trends in losses and costs are explored after adjusting losses for shifting financial and societal changes, and from these assessments, the key factors in climate and society that explain the trends are identified.

\section{Absolute trends}

Losses caused by catastrophes, defined by the property insurance industry as storms causing insured losses $>\$ 5$ million in the year of occurrence, have grown steadily from about $\$ 100$ million annually in the 1950 s to $\$ 6$ billion per year in the 1990 s, and the very costly events since 1949 are scattered randomly throughout the 1949-97 period (Changnon 1999b). Crop/hail insurance losses, another relatively long and consistent measure of losses from hail and wind, have also grown steadily, rising from an annual average of $\$ 30$ million (year of occurrence) in the 1950s to $\$ 320$ million annually in the 1990s (Changnon et al. 1997). Federal relief payments for weather disasters grew from $\$ 670$ million in $1996-70$ to $\$ 4$ billion in 1991-95 (Sylves 1998).

Losses created by various weather types have also grown. Annual hurricane losses have grown from $\$ 5$ billion in the 1940s to more than $\$ 40$ billion in the 1990s, adjusted for inflation to 1990 dollars (Pielke and Landsea 1998). Flood damages, which rank as the top weather-caused losses in the nation, also continue to increase with annual losses of $\$ 1$ billion in the 1940 s, growing to $\$ 6$ billion per year during the 1980s-90s (Pielke 1999a). Damaging hailstorms causing urban losses in excess of $\$ 300$ million have become common in the 1990s as evidenced by record storms in Denver, Dallas, Oklahoma City, Wichita, Orlando, and Fort Worth (Changnon 1997). Tornado losses increased from an annual average of \$325 million in the 1950 s to $\$ 370$ million in the 1990 s, and windstorm losses escalated from $\$ 153$ million per year in midcentury to $\$ 1.2$ billion per year in the 1990s.

Trends in insured loss statistics show sharp regional differences. In the West Coast, the Arizona-ColoradoNew Mexico-Texas area, and the Southeastern coastal states, the number of property catastrophes causing $>\$ 100$ million in losses during 1990-97 has been double those in the prior 40 years (Changnon 1999b). Elsewhere, recent costly storms are up but only 20 to 
40 percent over the prior 40 -yr period. Crop/hail insurance losses show major regional differences too, with rapid increases during the 1990s in the high plains but with decreases since 1980 in the Midwest (Changnon 1997).

Weather-related loss of life has not shown the overall increase found in dollar losses. The number of deaths related to tornadoes, hurricanes, and severe storms has either decreased or remained unchanged over the past 20 years (Kunkel et al. 1999). The lack of an increase in weather deaths, given an evergrowing population, is largely attributed to better forecasting, improved warning systems, and greater awareness of risks. The only weather hazards showing increases in mortality have been those due to flooding and to heat waves (Kunkel et al. 1999). Heat wave deaths were exceptionally high in 1980, 1988, and 1995 (Changnon et al. 1996).

\section{Data used to define trends in economic losses}

There is no single source of data on all types of financial losses caused by weather extremes or any other type of natural disasters. This problem involving the costs of disasters has been the subject of two recent major national assessments of loss data (CACNH 1999; Heinz Study Group 1999). It is often difficult to find systematic data on losses since many storm damages go unrecorded and must be estimated. Insurance loss data and government relief-assistance payments are systematic sources of data, but many uninsured losses are experienced by individuals and business and it is difficult to get accurate estimates of these losses. The measurement and estimation of losses from atmospheric extremes, including the loss of life due to heat stress, are fraught with uncertainties. Investigations require multidisciplinary expertise and assessment of many difficult to access data sources, and as a result, the research is often expensive. Major damaging events like Hurricane Andrew, the 1993 Midwestern flood, and the record 1988-89 drought often lead to detailed studies of the losses (Riebsame et al. 1991; Changnon 1996a; Pielke 1995), but losses from most less-than-record events are not as well examined.

The most consistent long-term storm loss data are those compiled by the insurance industry, but these require careful interpretation and represent only a subset of the total losses (CACNH 1999). Unfortunately, insurance data on losses resulting from climatic ex- tremes such as major floods and droughts are limited-the insured losses from the 1993 record Midwestern flood were less than $\$ 0.4$ billion in an event with total losses assessed as $\$ 19$ billion (Changnon 1996b). Other often ignored and unmeasured yet highly important loss values resulting from weatherclimate extremes are the delayed, indirect losses such as lost sales or spending reductions, both of which result in income losses, closure of firms, cutbacks, or shifts of business to locations beyond the damaged area (CACNH 1999). Thus, determination of the economic losses caused by extreme conditions requires assessment of many data sources, adjustment of the data for temporal changes in inflation and other factors affecting losses, and a combination of a variety of data and information to obtain a composite measure of the total direct and indirect losses. Any analysis of trends must pay careful attention to methodology (Kunkel et al. 1999).

\section{Assessment of trends and their causes}

Insurance loss data represent one of the best longterm records of weather losses in the United States for defining trends. But, they cannot be taken at face value, and must undergo several adjustments to address changes in inflation, liability (amounts and location) in land and property values, and in wealth, all of which must be done before the raw loss data can be meaningfully assessed (Changnon and Changnon 1998). The crop/hail insurance industry devised an annual index by adjusting losses for liability $(\$)$ to obtain a measure useful in comparing losses between years (Changnon and Changnon 1997). Their adjusted national loss values show peaks in the late 1950s-early 1960s and again in the early 1990s but the 50-yr trend is flat.

When the property catastrophe loss data undergo adjustments for various insurance shifts and changes in insured exposures, the revised temporal trends are drastically changed from those based on the actual loss values. The historical records of catastrophes causing $>$ \$100 million, based on adjusted storm values to 1992 dollars, show relatively high values of 5 to 7 costly storms per year in the 1949-65 period, decreasing to 1 to 3 storms per year from the late 1960s into the early 1980s, and then an increase to 10 to 12 storms per year in the 1990s (Changnon et al. 1997). Federal weather disaster relief payments also did not increase during 


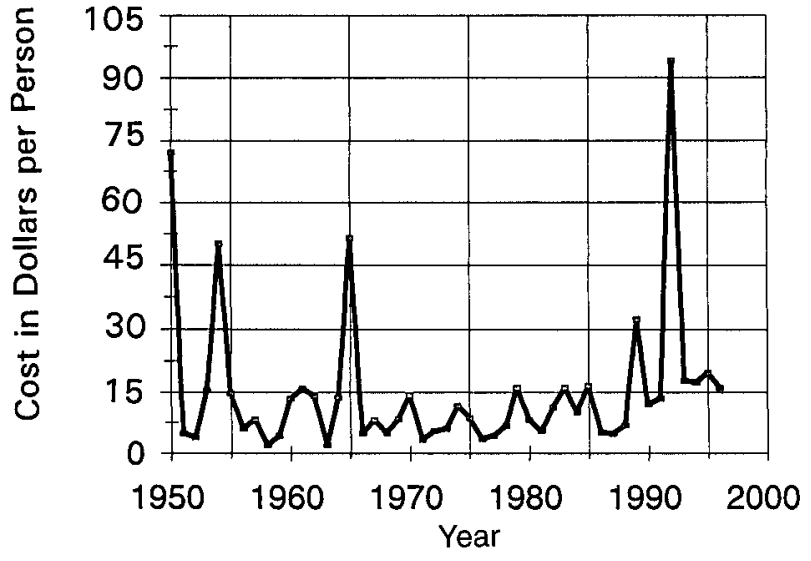

FIG. 2. The annual insured property losses in the United States from weather extremes divided by the annual U.S. population during 1950-96, producing a per capita loss value for each year (Changnon 1999b).

the 1970s and 1980s, holding at an annual average of \$225 million (1994 dollars), but then they rapidly increased to an average of $\$ 800$ million per year during the 1990s (Sylves 1998).

As shown in Fig 2, the annual insured property losses, when divided by annual United States population values, produce a flat trend from 1949 through 1996 with isolated loss peaks in six years when major hurricanes occurred such as Hugo in 1989 and Andrew and Iniki in 1992 (Changnon 1999a). This curve is quite different from the unadjusted values of Fig. 1. Catastrophes causing $>\$ 100$ million, after adjustment, averaged $\$ 551$ million in loss per event in the 1990s, just $\$ 12$ million higher than the average of the 142 catastrophes in the prior 40 years, revealing that storm intensity had not substantially increased (Changnon 1999b). An extensive study of hurricane losses since 1920 revealed that after adjustment, the losses due to hurricanes have been decreasing with time, not increasing as the raw dollar losses showed, and this decrease is consistent with the observed downward climatic trend in hurricane frequency (Pielke and Landsea 1998). The historical record of adjusted property hail losses shows a recent peak in the 1990s but with comparable earlier peaks in the 1950s and 1960s (Changnon 1997).

Thus, trends in most storm loss data, after careful adjustment for societal and insurance factors, do not display upward trends with time, but rather are flat trends with random appearing fluctuations over the past 40 to 60 years. When this information is compared with the sharp upward trends in actual dollar losses, and when this information is coupled with the loca- tions of where the losses have grown the most (Southeast, South, and West), the results collectively indicate that the major cause of trends in losses related to weather and climate extremes is societal factors: the growth of wealth with more valuable property at risk, increasing density of property, and demographic shifts to coastal areas and storm-prone areas that are experiencing increasing urbanization (Kunkel et al. 1999). Field investigations of Hurricane Andrew's losses also showed building codes had not been followed, increasing losses by an estimated $\$ 4$ to $\$ 6$ billion (Roth 1996). Studies regarding deaths caused by heat waves, largely occurring in the core of large cities of the northern United States, have found that changes in certain societal factors such as age and poverty level largely explain why recent heat waves have caused more deaths than those from earlier strong heat waves (Changnon et al. 1996). The continuing growth in deaths caused by floods is also partly the result of social behavior, and whether the actual increases in hydrologic-defined floods contribute to this remains an open question (Pielke 1999b). Thus, the results from most studies show there has been an overall increase in the nation's vulnerability to weather and climate extremes.

Loss trends can also be a function of shifts in extreme weather-climate events, as noted in accompanying papers. A recent comparative investigation of trends in losses and trends in storm activity revealed that for many weather extremes including hailstorms, thunderstorms, tornadoes, droughts, and hurricanes there were no long-term increases during the last 30 to 50 years comparable to the observed trends in losses (Kunkel et al. 1999). That study did find increases in winter storms along the East Coast and in precipitation.

Many trends in climate extremes defined statistically as infrequent events and of interest climatically have few or indiscernible societal impacts. For example, a noted statistically significant increase from 1910 to 1995 in days with rain $>5.1 \mathrm{~cm}$ across most of the United States is climatologically important, representing less than 5\% of all rain days (Karl and Knight 1998). This could be thought to have affected the frequency of damaging floods. However, the relationship of such rain events to major flood flows or the incidence of damaging floods has not been established (Pielke 1999b). Studies of river basins in the Midwest showing increases of 33\%-60\% in annual peak flood flows over 50 years (1940-90) revealed that $55 \%-85 \%$ of the increases were due to land-use changes with only $15 \%-45 \%$ due to temporal increases in the heavy precipitation associated with the 
floods (Changnon and Demissie 1996). Societal effects acted to mask and confound the detection of the physical effects from the rain extremes, and the landuse changes were larger than the effects of sizable precipitation changes. Such masking effects can also include numerous and sizable past human adjustments to a variety of historical extremes such as floods, droughts, and freezes. Flash floods in confined basins create notable impacts on property and cause most flood-related deaths. Storms producing flash floods typically produce $20-45 \mathrm{~cm}$ of rain in a few hours, a rare climate extreme rated as an event expected to occur only once in 100-500 years for a given locale. These examples suggest that the search for changes in climate conditions meaningful to society should begin with impacts and societal vulnerabilities and from those, one can identify the climate conditions of significance.

\section{Summary}

Societal impacts from weather and climate extremes, and trends in those impacts, are a function of both climate and society. Comprehensive assessments of losses and results from several recent studies of extremes establish that losses related to most weatherclimate extremes have been on the rise. But, after adjustment of the data for major societal changes, most losses from weather-climate extremes are not increasing. This indicates that most upward changes are due to a mix of societal factors. Geographical locations of the large loss trends further reveal that population growth and demographic shifts are playing a major role in the degree of increasing losses from weatherclimate extremes. The United States is becoming ever more vulnerable to extremes, even with large expenditures on technology based systems (van der Link et al. 1998; Kunreuther 1998), and without major changes in societal responses to weather and climate extremes, it is reasonable to predict ever-increasing losses even without any detrimental climate changes (Larson 1998). Any climate changes would exacerbate the existing vulnerability. Recognition of these trends in societal vulnerability to weather extremes suggests that the present focus on mitigating greenhouse effect should be complemented by a greater emphasis on adaptation (Pielke 1998; Changnon 1995). National attention to the mitigation of the rapidly growing losses from natural hazards has increased, and the Institute for Business and Home Safety, recently formed by the insurance industry, is working with the government to promote adaptive measures like improved construction practices (Changnon et al. 1999).

Although it is difficult and often expensive to gain a reasonably accurate measure of weather losses, it is essential to develop and maintain a clear picture of the impacts and their trends for policy, planning, and mitigative activities. Identifying and understanding this societal vulnerability has great advantages: it allows society to avert future losses through adapting to and preparing for the vicissitudes of weather and climate extremes.

\section{References}

American Insurance Association, 1999: Property-Casualty Insurance and the Climate Change Debate: A Risk Assessment, $11 \mathrm{pp}$. [Available from American Insurance Association, 1818 G St. NW, Washington, DC 20006.]

Bi-Partisan Task Force on Funding Disaster Relief, 1996: Federal Disaster Assistance. Document 104-4, U.S. Government Printing Office, Washington, DC, 125 pp.

CACNH, 1999: The Costs of Natural Disasters: A Framework for Assessment. National Academy of Sciences, $68 \mathrm{pp}$.

Changnon, D., and S. A. Changnon, 1997: Surrogate data to estimate crop-hail loss. J. Appl. Meteor., 36, 1202-1210.

$\longrightarrow$, and _ 1998: Evaluation of weather catastrophe data for use in climate change investigations. Climatic Change, 38, $435-445$.

Changnon, S. A., 1995: Adaptation to climate change: The likely outcome. Preparing for Global Change: A Midwestern Perspective, G. R. Carmichael, Ed., Academic Publishing, 47-65.

- 1996a: Defining the flood: A chronology of key issues. The Great Flood of 1993, S. Changnon, Ed., Westview Press, 3-28. _ 1996 b: Losers and winners: A summary of the flood's impacts. The Great Flood of 1993, S. Changnon, Ed., Westview Press, 276-299.

_ 1997: Trends in hail in the United States. Proc. Workshop on the Societal and Economic Impacts of Weather, Boulder, CO, NCAR, 19-31.

$\ldots$, 1999a: Factors affecting temporal fluctuations in damaging storm activity in the U.S. based on insurance loss data. Meteor. Appl., 5, 125-135.

__ 1999b: Record high losses for weather disasters in the United States during the 1990s: How excessive and why? Natural Hazards, 18, 287-300.

_ , and M. Demissie, 1996: Detection of changes in streamflow and floods resulting from climate fluctuations and land use changes. Climatic Change, 36, 411-421.

_ K. K. Kunkel, and B. Reinke, 1996: Impacts and responses to the 1995 heat wave: A call to action. Bull. Amer. Meteor. Soc., 77, 1497-1506.

- D. Changnon, E. R. Fosse, D. Hoganson, R. J. Roth Jr., and J. Totsch, 1997: Effects of recent extremes on the insurance industry: Major implications for the atmospheric sciences. Bull. Amer. Meteor. Soc., 78, 425-435. 
— E. Lecomte, and E. R. Fosse, 1999: Interactions between the insurance industry and atmospheric sciences. Climatic Change, 42, 51-67.

Flavin, C., 1994: Storm warnings. World Watch, 7, 10-20.

Heinz Study Group, 1999: The Hidden Costs of Coastal Hazards: Implications for Risk Assessment and Mitigation, Island Press, $119 \mathrm{pp}$.

IPCC, 1996: Climate Change 1995: The Science of Climate Change. Cambridge University Press, $231 \mathrm{pp}$.

Karl, T. R., and R. W. Knight, 1998: Secular trends of precipitation amount, frequency, and intensity in the United States. Bull. Amer. Meteor. Soc., 79, 231-241.

Kunkel, K. E., R. A. Pielke Jr., and S. A. Changnon, 1999: Temporal fluctuations in weather and climate extremes that cause economic and human health impacts: A review. Bull. Amer. Meteor. Soc., 80, 1077-1098.

Kunreuther, H., 1998: Introduction. Paying the Price, H. Kunreuther and R. Roth, Eds., J. Henry Press, 1-16.

Larson, E., 1998: Waiting for Hurricane X. Time, 52, 63-64.

Lecomte, E., 1993: Remarks. Climate Change and the Insurance Industry: The Next Generation. College of Insurance, 13-18.

Pielke, R. A., Jr., 1995: Hurricane Andrew in South Florida. National Center for Atmospheric Research, 79 pp.

- 1997: Executive summary. Proc. Workshop on the Social and Economic Impacts of Weather, Boulder, CO, NCAR, 310 .
1998: Rethinking the role of adaptation in climate policy. Global Environ. Change, 8, 159-170.

_ 1999a: Nine fallacies of floods. Climatic Change, 42, 118127.

, 1999b: Flood impacts on society: Damaging floods as a framework for assessment. Floods, D. J. Parker, Ed., Routledge Press, $40 \mathrm{pp}$.

_- and C. W. Landsea, 1998: Normalized hurricane damages in the United States: 1925-95. Wea. Forecasting, 13, 621631.

Riebsame, W. E., S. A. Changnon, and T. R. Karl, 1991: Drought and Natural Resources Management in United States. Westview Press, 174 pp.

Roth, R. J., Sr., 1996: The property casualty insurance industry and the weather of 1991-1994. Impacts and Responses of the Insurance Industry to Recent Weather Extremes, S. Changnon, Ed., Changnon Climatologist, 101-132. [Available from Changnon Climatologist, 801 Buckthorn, Mahomet, IL 61853.]

Sylves, R., 1996: Disaster Management in the U.S. and Canada. Charles C. Thomas Publishers, 45 pp.

_ 1998: Disasters and Coastal Zone States. University of Delaware Sea Grant Program, 125 pp.

van der Link, G., and Coauthors, 1998: Why the U.S. is becoming more vulnerable to natural disasters. Eos, Trans. Amer. Geophys. Union, 79, 536-537. 